\title{
DPPH-Scavenging and Antimicrobial Activities of Asteraceae Medicinal Plants on Uropathogenic Bacteria
}

\author{
Phan-Canh Trinh (D), Le-Thi-Thanh Thao, Hoang-Tran-Viet Ha, and TuAnh Nguyen \\ Department of Microbiology and Parasitology, Faculty of Pharmacy, University of Medicine and Pharmacy at Ho Chi Minh City, \\ Ho Chi Minh 700000, Vietnam \\ Correspondence should be addressed to Phan-Canh Trinh; phancanhtrinh@ump.edu.vn
}

Received 10 November 2019; Revised 14 April 2020; Accepted 20 April 2020; Published 15 May 2020

Academic Editor: I-Min Liu

Copyright (c) 2020 Phan-Canh Trinh et al. This is an open access article distributed under the Creative Commons Attribution License, which permits unrestricted use, distribution, and reproduction in any medium, provided the original work is properly cited.

\begin{abstract}
Asteraceae species were widely applied in traditional medicines in Asian countries as sources of natural antioxidants and antimicrobial agents. This study aimed to evaluate DPPH-scavenging capacities and antimicrobial activities of nine Asteraceae species collected from Southern Vietnam. Antioxidant and antimicrobial activities were determined by standard protocols. Essential oils from Ageratum conyzoides, Helianthus annuus, and Artemisia vulgaris indicated significant inhibitory effects on Staphylococcus aureus and Candida spp. Crude extracts and fractions from Taraxacum officinale, Chrysanthemum morifolium, A. conyzoides, and Tagetes erecta showed inhibitory ability on at least one testing bacterial strains including S. aureus, Escherichia coli, Klebsiella pneumoniae, and Pseudomonas aeruginosa. In a study on clinical isolates, ethyl acetate fraction from $A$. conyzoides flower displayed the most potent effect on uropathogenic $E$. coli and $K$. pneumoniae with MIC at $1.25-10 \mathrm{mg} / \mathrm{ml}$ and $5-12.5 \mathrm{mg} / \mathrm{ml}$, respectively. DPPH-scavenging assay indicated that T. erecta extract had the lowest $\mathrm{IC}_{50}(17.280 \mu \mathrm{g} / \mathrm{ml})$ and is 2.4 times higher than vitamin $\mathrm{C}(7.321 \mu \mathrm{g} / \mathrm{ml})$. This study revealed that $A$. conyzoides has good potential against uropathogenic E. coli and K. pneumoniae, and therefore could be applied for prophylactic treatment of urinary infection.
\end{abstract}

\section{Introduction}

In recent years, antibiotic resistance has become more sophisticated, putting mankind into the postantibiotic era. Many clinical Enterobacteriaceae strains such as Escherichia coli and Klebsiella pneumoniae have extended-spectrum beta-lactamase (ESBL) and carbapenem-resistant Enterobacteriaceae (CRE) [1-3]. Polymyxin plasmid-mediated resistance gene (mcr-1) especially was observed in E. coli strains, which was isolated from animals and in patients with infection during 2011-2014, in China [4]. Moreover, it is with profound concern that mcr-1 could be transferred to $K$. pneumoniae and Pseudomonas aeruginosa via transformation [4]. In 2016, the first report about mcr-1 gene in a patient with urinary tract infections (UTIs) in Pennsylvania, the United States, was shown by Abbasi [5]. According to recent reports, the causative agents of UTIs include uropathogenic E. coli, Klebsiella pneumoniae, Enterococcus spp., Staphylococcus saprophyticus, group B Streptococcus (GBS), Proteus mirabilis, Pseudomonas aeruginosa, Staphylococcus aureus, and Candida spp. [6-10], in which Escherichia coli is the most common causative agents of both uncomplicated and complicated UTIs [6].

Herbal extracts and essential oils were used as foods such as floral beverages, functional foods, and traditional medicines in many years, with minimal known "side effects" on human health. Using herbal remedies might help in reducing dependence on antibiotic therapies and minimizing antibiotic resistance [11].

The Asteraceae family (Compositae) is a widespread family of flowering plants, including 32,913 species names, belonging to 1,911 plant genera, distributed in 13 subfamilies [12]. The tropics, subtropics, and temperate regions are the natural habitats of Asteraceae species [13]. They usually 
contain a large amount of essential oil, polyphenols, and flavonoid compounds, which are often studied for antimicrobial and antioxidant activities [14-19].

Although there were many reports for antimicrobial and antioxidant effects of Asteraceae species, applications of these extracts in treating infectious diseases need an evaluation of pathogenic bacterial strains isolated from clinical specimens [11]. In the study, we screened antimicrobial and antioxidant activities of ethanol extracts and essential oils from nine species of Asteraceae on 30 clinical strains causing urinary tract infection, collected from District 2 Hospital, Ho Chi Minh City, Vietnam. The target was seeking the best extract to apply for a healthcare serum to prevent recurrent UTIs. The antioxidant activity might be a protective factor for urinary tract epithelium to avoid the impact of oxidative stress.

\section{Materials and Methods}

We conducted investigations on antimicrobial activities of nine Asteraceae species collected from Southern Vietnam, following Figure 1. In particular, after pretreating and extracting herbal samples to obtain crude extracts and essential oils, we evaluated the antimicrobial effect by applying the diffusion method. The extracts which show activity were fractionated by $n$-hexane, chloroform, and ethyl acetate, respectively. The well-agar-diffusion method was used to determine the antimicrobial capacities of fractions. Fractions which indicated inhibitory zone were evaluated with MIC and MBC. DPPH free-radical scavenging assays were carried out on crude extracts $[20,21]$.

2.1. Plant Authentication and Preparation. Asteraceae-plant samples were collected from Southern Vietnam from March to May 2016. These samples were identified at the Botany Department, Faculty of Pharmacy, University of Medicine and Pharmacy at Ho Chi Minh City. These species are usually used as traditional medicines in Vietnam. Table 1 shows common names and general uses following the botanical nomenclature of nine species used in this study.

After harvesting, the samples were washed under running water to remove dust and rinse with distilled water to drain. Subsequently, they were dried in the shade, and afterwards the dried plant materials were finely grounded by mechanical grinders. The powder was stored in tightly closed glass containers in the dark at room temperature.

\subsection{Preparation of Plant Extracts}

2.2.1. Preparation of Essential Oils. Plant samples were cut into small pieces after washing under running water. Plant materials $(100 \mathrm{~g})$ were placed in a flask $(1 \mathrm{~L})$ together with distilled water. Clevenger apparatus was used for distillation of essential oils. After steam distillation (about 3 hours), the oil was isolated and dried over anhydrous sodium sulfate (Merck). The essential oils were used directly for antimicrobial assay.
2.2.2. Ethanol Crude Extracts. Plant materials $(50 \mathrm{~g})$ were extracted by cold soaking with $500 \mathrm{ml}$ of $96 \%$ ethanol (Xilong Chemical) for 24 hours at 10:1 solvent-to-sample ratio $(\mathrm{v} / \mathrm{w})$. Then, the mixtures were filtered through Whatman filter paper. The extracts were allowed to evaporate at a temperature of $45-50^{\circ} \mathrm{C}$ with water bath WNB 29 (Memmert). These steps were repeated three times to achieve maximal extraction of compounds. Dried crude extracts were weighed and kept at $-35^{\circ} \mathrm{C}$ till further use (not more than one month). These extracts had been screened for antimicrobial activity with well agar diffusion method to choose the good antimicrobial extracts for the next step.

\subsubsection{Fractionation of the Ethanol Crude Extracts.} Ethanol crude extracts, which possess the strong antimicrobial effect, were subjected to liquid/liquid extraction with $n$-hexane, chloroform, and ethyl acetate, respectively. After evaporating solvent, the antimicrobial activity was determined for each fraction.

Stock solutions of crude extracts and fractions were prepared at a concentration of $100 \mathrm{mg} / \mathrm{ml}$ in $10 \%$ dimethyl sulfoxide (DMSO, Merck).

2.3. Preliminary Phytochemical Screening. The ethanol crude extracts were analyzed for phytochemical constituents for the identification of various classes of compounds, according to Maria et al. [32].

2.4. Microorganism Strains and Culture Conditions. Microbial strains from American Type Culture Collection (ATCC) were used in this study for preliminary antimicrobial assays, which included methicillin-sensitive Staphylococcus aureus ATCC 25923 (SA), methicillin-resistant $S$. aureus ATCC 33591 (SR), Enterococcus faecalis ATCC 29212 (EF), Escherichia coli ATCC 25922 (EC), Klebsiella pneumoniae ATCC 35657 (KP), Pseudomonas aeruginosa ATCC 27853 (PA), and Candida albicans ATCC 10231 (CA). Two clinical non-albicans strains, Candida glabrata ND31 (CG) and Candida tropicalis PNT20 (CT), which were provided by Anh et al. [33] and clinical isolates (15 E. coli and $15 \mathrm{~K}$. pneumoniae), which were isolated from District 2 Hospital, Ho Chi Minh City, Vietnam, in 2016, were also applied for antimicrobial investigation on the potential extracts.

These strains were preserved in $25 \%$ glycerol at $-80^{\circ} \mathrm{C}$. One strain tube was thawed rapidly at $37^{\circ} \mathrm{C}$ and cultured in $10 \mathrm{ml}$ Brain heart infusion (BHI, Merck) at $37^{\circ} \mathrm{C}$ over 24 hours. The bacteria were streaked on BHI agar (BHA, Merck) at $37^{\circ} \mathrm{C}$ over 24 hours. One to five colonies were used to prepare bacterial suspension to match a $0.5 \mathrm{McF}$ arland standard $\left(1-1.5 \times 10^{8} \mathrm{CFU} / \mathrm{ml}\right)$. Mueller-Hinton agar medium (MHA, Merck) and MHA supplied 2\% glucose medium (MHGA, Merck) were used for determination antibacterial and antifungal activity, respectively.

2.5. Antimicrobial Diffusion Method. The antimicrobial activity of the samples was initially evaluated by the well agar diffusion assay for the extracts and disc diffusion assay for 


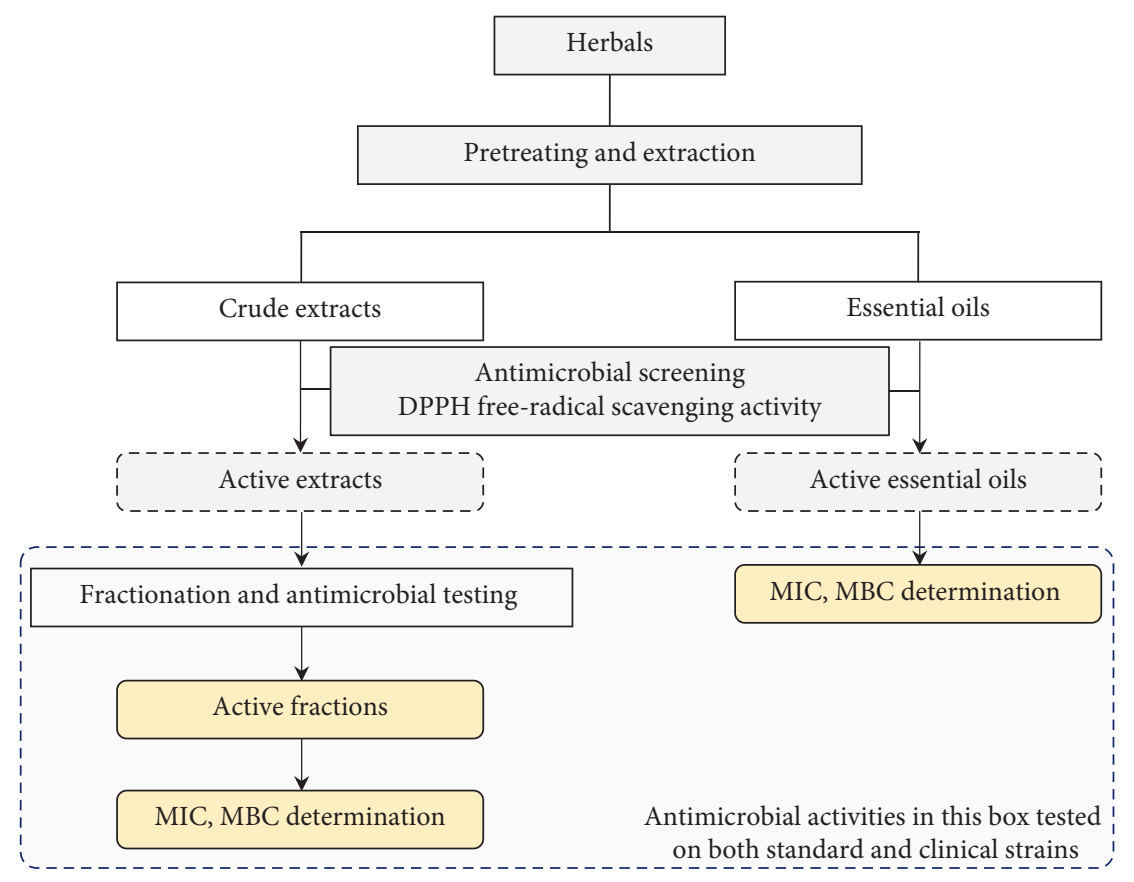

FIGURE 1: Schematic representation of the experimental layout.

TABLE 1: The investigated plants.

\begin{tabular}{lccc}
\hline Nomenclature & Common name & Traditional uses* $^{*}$ & Part tested $^{\dagger}$ \\
\hline Ageratum conyzoides L. & Billygoat weed & Sinusitis, anti-inflammation [22] & Aerial parts, essential oils [22] \\
Artemisia vulgaris L. & Mugwort & Skin ailments, wounds, ulcers [23] & Aerial parts, essential oils [23] \\
Chrysanthemum coronarium L. & Crown daisy & Pain relief, fever, dysentery [24, 25] & Aerial parts [25] \\
Chrysanthemum morifolium Ramat. & Florists chrysanthemum & Pimples, dermatitis, fevers [26] & Flowers [26] \\
Helianthus annuus L. & Sunflower & Anti-inflammatory, malaria [27] & Flowers, essential oils [27] \\
Tagetes erecta L. & Mexican marigold & Dysentery, asthma, ulcer [28] & Flowers [28] \\
Taraxacum officinale F. H. Wigg. & Dandelion & Hepatitis, bronchitis, pneumonia [29] & Aerial parts [29] \\
Vernonia amygdalina Del. & Bitter leaf & Fever, measles, parasites [30] & Leaves [30] \\
Wedelia trilobata L. & Wedelia & Fever, infection [31] & Aerial parts [31] \\
\hline
\end{tabular}

${ }^{*}$ In this column, there are presented only such traditional uses which can imply the presence of antimicrobial compounds. ${ }^{\dagger}$ Part tested: the part of the plant used in this study.

the essential oils [21]. The growth medium was poured into Petri dishes at $45-50^{\circ} \mathrm{C}$, approximately $4 \mathrm{~mm}$ depth, and they were left to solidify in the laminar-flow hood. Subsequently, a sterile cotton swab was dipped into overnight microbial suspensions (adjusted to a turbidity of $0.5 \mathrm{McF}$ arland standard). Agar plates were inoculated by evenly streaking cotton swab over the agar medium.

As for extracts, wells with a diameter of $6 \mathrm{~mm}$ were cut in the inoculated-agar medium with a sterile cork borer. Stock solutions of the samples were diluted in sterile distilled water to get $100 \mathrm{mg} / \mathrm{ml}$ concentration. The tested samples and controls $(50 \mu \mathrm{l})$ were dispensed into the wells.

As for essential oils, $20 \mu \mathrm{l}$ of the oils was applied on filter paper discs $(6 \mathrm{~mm})$. These discs were put on the inoculatedagar surface.

The plates were incubated at $37^{\circ} \mathrm{C}$ for $24-48$ hours. After that, the diameters of growth inhibition zones were measured by the electronic vernier caliper (Insize 1112-200). The following control agents were used: positive control agents, ampicillin $20 \mu \mathrm{g} / \mathrm{ml}$ (for bacteria) and ketoconazole $20 \mu \mathrm{g} / \mathrm{ml}$ (for yeasts); negative control agent, 10\% DMSO.
2.6. Determination of Minimum Inhibitory Concentration. Determination of minimum inhibitory concentrations (MIC) of the extracts and essential oils was done using the agar dilution method [21]. Stock solutions were diluted with melted agar to a concentration range so that the following concentration is equal to half the previous concentration. Subsequently, the agar was poured into Petri discs and waited for them to solidify in the laminar-flow hood. Microorganism suspensions at $0.5 \mathrm{McF}$ arland were diluted by $0.85 \% \mathrm{NaCl}$ solution to reach $1-1.5 \times 10^{7} \mathrm{CFU} / \mathrm{ml}$ for bacteria and $1-5 \times 10^{6} \mathrm{CFU} / \mathrm{ml}$ for Candida spp. These suspensions were spotted $(1 \mu \mathrm{l})$ on the agar surface. Bacterial or yeast colonies growth at the spot after incubating at $37^{\circ} \mathrm{C}$ for 24-48 hours indicated for the assay. The MIC is the lowest concentration of antimicrobial agent that completely inhibits growth. The experiment was replicated three times.

2.7. Determination of Minimum Bactericidal Concentration. To determine the minimal bactericidal concentration (MBC), the spots at MIC, 2MIC, 4MIC, and 8MIC were 
washed with $1 \mathrm{ml}$ of $0.85 \% \mathrm{NaCl}$. The $100 \mu \mathrm{l}$ of the washing suspension was spread evenly over BHA agar. After 24-48 hours of incubation at $37^{\circ} \mathrm{C}$, the number of surviving bacteria was determined. The MBC was defined as the lowest extract concentration at which $99.9 \%$ of the bacteria have been killed. The experiment was replicated three times.

2.8. DPPH Free-Radical Scavenging Activity Assay. The $0.25 \mathrm{mg} / \mathrm{ml}$ 2,2-diphenyl-1-picryl-hydrazyl-hydrate (DPPH, Sigma Aldrich) solution in methanol (working solution) was used to determine the antioxidant capacity. Stock solutions were prepared at the sample concentration of $10 \mathrm{mg} / \mathrm{ml}$. The preliminary tests were carried out on TLC Silica gel $60 \mathrm{~F}_{254}$ (Merck). After impregnating $2 \mu \mathrm{l} /$ spot of stock solutions on the TLC plate, the plate was dipped into the DPPH working solution and incubated at the room temperature 30 minutes. The positive test indicated the yellow on the violet background [34].

Reaction mixtures consisted of stock solution, $2 \mathrm{ml} \mathrm{DPPH}$ working solution, and methanol as a solvent to have a sample concentration from 0.1 to $0.5 \mathrm{mg} / \mathrm{ml}$. The negative controls had only the solvent instead of the testing solution. The mixtures were incubated for 30 minutes at $37^{\circ} \mathrm{C}$ in the dark. The decrease in the absorbance at $517 \mathrm{~nm}$ was measured $\left(A_{E}\right)$ [34]. The experiment was carried out in triplicate. Samples and positive control ascorbic acid were tested in triplicate over the same range of sample concentrations. Radical scavenging activity was calculated using the following formula:

$$
\mathrm{SC} \%=100 \% x \frac{\left(A_{B}-A_{E}\right)}{A_{B}}(\%),
$$

where $A_{B}$ is absorbance of the blank sample and $A_{E}$ is absorbance of the plant extract.

The antioxidant activity was expressed as the $\mathrm{IC}_{50}$ value. This value was determined from the plotted graphs of scavenging activity against the concentration of the sample.

\section{Results and Discussion}

\subsection{Results}

3.1.1. Preliminary Phytochemical Screening. Table 2 depicts various classes of phytoconstituents presenting in testing herbs. In general, tannins, flavonoids, and phenolics were found in all testing herbs. A. conyzoides, $H$. annuus, and $A$. vulgaris possess a large amount of essential oil.

3.1.2. Antimicrobial Screening Assay. Among ethanol crude extracts tested, there were four plant species including Ageratum conyzoides, Chrysanthemum morifolium, Tagetes erecta, and Taraxacum officinale indicating the antibacterial activities from one to four standard bacterial strains. None of them had the anti-yeast activity on three yeast strains listed in Table 3. To be more specific, A. conyzoides and T. erecta expressed the broad-spectrum antimicrobial effect on Grampositive (20-22 mm on MSSA and MRSA) and Gramnegative bacteria (11-18 $\mathrm{mm}$ ) while simultaneously $T$. erecta manifested the inhibitory capacity on $P$. aeruginosa $(13 \mathrm{~mm})$.
Besides, C. morifolium and T. officinale indicated the activity only on methicillin-sensitive $S$. aureus.

The ethanol crude extracts, which showed antimicrobial activity (active extracts), were decanted with different polarization solvents including $n$-hexane, chloroform, and ethyl acetate to obtain fractions. The diffusion method was conducted to determine antimicrobial activities of these fractions on microbial strains. Noticeably, antimicrobial agents are usually distributed in moderate polarity fractions such as chloroform and ethyl acetate (Table 4). The ethyl acetate fraction of $A$. conyzoides displayed the IZD on MSSA $(23 \mathrm{~mm})$, MRSA $(21 \mathrm{~mm})$, K. pneumoniae $(15 \mathrm{~mm})$, and $E$. coli $(14 \mathrm{~mm})$. Similarly, T. erecta's fraction of ethyl acetate shows IZD from 11 to $18 \mathrm{~mm}$ on MSSA, MRSA, K. pneumoniae, and $P$. aeruginosa.

The essential oils of $A$. conyzoides (aerial parts), A. vulgaris (aerial parts), and $H$. annuus (flowers) demonstrated antimicrobial activities (Table 5). Although ethanol crude extracts of $A$. vulgaris and $H$. annuus do not have inhibitory capacity on testing microorganisms, this test revealed the effect of their essential oils on $S$. aureus and Candida spp.

MIC and MBC values of crude extracts and fractions from the four selected plant parts (Ageratum conyzoides, Chrysanthemum morifolium, Tagetes erecta, and Taraxacum officinale) were determined (Table 6).

MIC and MBC values of the three essential oils, $A$. conyzoides, A. vulgaris, and $H$. annuus, were shown in Table 7.

Through these results, we found effects of extracts from $A$. conyzoides and T. erecta against $E$. coli and $K$. pneumoniae being two leading infectious agents in UTIs. In order to explore the best extract to prevent recurrence UTIs, we evaluated the crude extracts and fractions of A. conyzoides and T. erecta on $15 \mathrm{E}$. coli and $15 \mathrm{~K}$. pneumoniae isolates from urine specimens at District 2 Hospital, Ho Chi Minh City.

The well agar diffusion assay was used for analyzing the activity of the investigated extracts. The results showed that only the ethyl acetate fraction from A. conyzoides had antibacterial activity against tested isolates. MIC values of the ethyl acetate fraction of $A$. conyzoides were determined by the agar dilution assay on the isolates of E. coli and K. pneumoniae that had minimum and maximum diameters of growth inhibition zone and on ESBL-producing isolates. The width of inhibition zones and minimum inhibitory concentration (MIC) is shown in Table 8. In detail, the IZD on E. coli and K. pneumoniae is indicated from $10.83 \mathrm{~mm}$ (E3) to $23.72 \mathrm{~mm}$ (E72) and from $9.33 \mathrm{~mm}$ (K18) to $19.73 \mathrm{~mm}$ (K17), respectively. A. conyzoides's ethyl acetate fraction displayed MIC values on E3, E72, K17, and K18 being 12.5, 5, 10, and $1.25 \mathrm{mg} / \mathrm{ml}$, respectively. ESBL-producing strains, E68, and K26 expressed MIC 6.25 and $2.5 \mathrm{mg} / \mathrm{ml}$, respectively.

3.1.3. Free Radical Scavenging Activity. DPPH screening test showed the good antioxidant effects of all crude extracts and essential oils. Free-radical scavenging activity of total ethanol extracts was quantitatively determined using a DPPH assay. $\mathrm{IC}_{50}$ value represents the concentration of tested extract, at which the inhibition of test activity reached 50\% 
TABLE 2: Phytochemical profile of ethanol crude extracts.

\begin{tabular}{|c|c|c|c|c|c|c|c|c|c|}
\hline Group of compounds & TO & $\mathrm{CM}$ & $\mathrm{AC}$ & $\mathrm{CC}$ & HA & $\mathrm{VA}$ & $\mathrm{AV}$ & TE & WT \\
\hline Carotenoid & - & - & - & - & - & - & - & - & - \\
\hline Free triterpenoids & + & - & - & - & - & - & - & + & - \\
\hline Alkaloids & - & - & - & - & + & + & + & + & - \\
\hline Coumarins & - & - & - & - & - & - & - & - & - \\
\hline Anthraglycosides & + & - & - & - & - & + & - & - & - \\
\hline Flavonoids & ++ & +++ & ++ & + & ++ & + & + & +++ & + \\
\hline Heart glycolysis & - & - & - & - & - & - & - & - & - \\
\hline Tannins & +++ & ++ & +++ & + & ++ & ++ & ++ & +++ & ++ \\
\hline Phenolics & +++ & +++ & +++ & ++ & ++ & ++ & ++ & +++ & + \\
\hline Saponins & + & + & - & + & - & + & + & + & + \\
\hline Organic acids & - & - & - & - & - & - & - & - & - \\
\hline Reducing agent & + & + & + & + & + & + & + & + & + \\
\hline
\end{tabular}

TO: T. officinale; CM: C. morifolium; AC: A. conyzoides; CC: C. coronarium; HA: H. annuus; VA: V. amygdalina; AV: A. vulgaris; TE: T. erecta; WT: W. trilobata.

TABLE 3: The inhibitory zone diameter (IZD, mm) of the ethanol crude plant extracts determined by agar well diffusion assay.

\begin{tabular}{lccccccccc}
\hline \multirow{2}{*}{ Plant species } & \multicolumn{8}{c}{ Inhibitory zone diameter (mm) } \\
& SA & SR & EF & KP & EC & PA & CA & CG & CT \\
\hline A. conyzoides & 22 & 20 & - & 18 & 11 & - & - & - & - \\
T. erecta & 21 & 20 & - & 16 & - & 13 & - & - & - \\
C. morifolium & 14 & - & - & - & - & - & - & - & - \\
T. officinale & 10 & - & - & - & - & - & - & - & - \\
A. vulgaris & - & - & - & - & - & - & - & - & - \\
C. coronarium & - & - & - & - & - & - & - & - & - \\
H. annuus & - & - & - & - & - & - & - & - & - \\
V. amygdalina & - & - & - & - & - & - & - & - & - \\
W. trilobata & - & - & - & - & - & - & - & - & - \\
\hline
\end{tabular}

-: no inhibitory zone.

TABLE 4: IZD (mm) of the fractions determined by well agar diffusion assay.

\begin{tabular}{|c|c|c|c|c|c|c|c|}
\hline \multirow{2}{*}{ Plant species } & \multirow{2}{*}{ Part tested } & \multirow{2}{*}{ Fractions } & \multicolumn{5}{|c|}{ IZD (mm) } \\
\hline & & & SA & SR & KP & $\mathrm{EC}$ & PA \\
\hline \multirow{4}{*}{ A. conyzoides } & \multirow{4}{*}{ Aerial parts } & $n$ - hexane & - & - & - & - & - \\
\hline & & $\mathrm{CHCl}_{3}$ & 11 & 11 & - & - & - \\
\hline & & EtOAc & 23 & 21 & 15 & 14 & - \\
\hline & & $\mathrm{EtOH}$ & 9 & - & 10 & - & - \\
\hline \multirow{4}{*}{ T. erecta } & \multirow{4}{*}{ Flower } & $n$ - hexane & 11 & - & 11 & - & - \\
\hline & & $\mathrm{CHCl}_{3}$ & 11 & - & 10 & - & - \\
\hline & & EtOAc & 17 & 12 & 18 & - & 11 \\
\hline & & $\mathrm{EtOH}$ & - & - & - & - & - \\
\hline \multirow{4}{*}{ C. morifolium } & \multirow{4}{*}{ Flower } & $n$ - hexane & - & - & - & - & - \\
\hline & & $\mathrm{CHCl}_{3}$ & 13 & - & - & - & - \\
\hline & & EtOAc & 14 & - & - & - & - \\
\hline & & EtOH & - & - & - & - & - \\
\hline \multirow{4}{*}{ T. officinale } & \multirow{4}{*}{ Aerial parts } & $n$ - hexane & - & - & - & - & - \\
\hline & & $\mathrm{CHCl}_{3}$ & - & - & - & - & - \\
\hline & & EtOAc & 11 & - & - & - & - \\
\hline & & EtOH & - & - & - & - & - \\
\hline
\end{tabular}

-: no inhibitory zone.

(Figure 2). The results were graphed by Microsoft Excel 2016. The $\mathrm{IC}_{50}$ values of essential oils were too large (3000-6000 $\mu \mathrm{g} / \mathrm{ml})$, which were outside the linear range.
Table 5: Antimicrobial activity of the essential oils determined by disc diffusion assay.

\begin{tabular}{lccccccccc}
\hline \multirow{2}{*}{ Essential oils } & \multicolumn{1}{c}{ IZD $(\mathrm{mm})$} \\
& SA & SR & EF & KP & EC & PA & CA & CG & CT \\
\hline A. conyzoides & 15 & - & - & - & - & - & - & 8 & 10 \\
A. vulgaris & 23 & 10 & - & - & - & - & 14 & 15 & 16 \\
H. annuus & 10 & - & - & - & - & - & - & - & 11 \\
\hline
\end{tabular}

-: no inhibitory zone. MIC values of active extracts and essential oils on standard strains.

The crude extract of $T$. erecta flower showed the significant scavenging effect for free radicals with $\mathrm{IC}_{50}=17.3 \mu \mathrm{g} / \mathrm{ml}, 2.4$ folds comparing to ascorbic acid.

3.2. Discussion. Among the tested extracts and essential oils, there were four crude extracts (Ageratum conyzoides, Chrysanthemum morifolium, Tagetes erecta, and Taraxacum officinale) and three essential oils (A. conyzoides, A. vulgaris, and $H$. annuus) indicating the antimicrobial activity against nine bacteria and three yeast strains. While the crude extracts only had effects on bacteria, the essential oils had effects on both bacteria and yeast strains. There are many reports about antiseptic, antimicrobial, antioxidant, and insecticidal activities of essential oils [35]. Chemical constituents represented in essential oils are usually derived from terpenes, phenolic compounds, and aromatic or aliphatic acid esters, which can partition into the lipids of bacterial and mitochondrial membrane resulting in disturbing the cell structures. The death of cells is caused by leakage of a large number of essential molecules and ions from the bacterial cell [36].

In this research, the ethanol crude extract from Tagetes erecta flower showed the highest inhibitory effect on MSSA (0.78 mg/ml), MRSA (3.13 mg/ml), K. pneumoniae (1.25 mg/ $\mathrm{ml})$, and $P$. aeruginosa $(2.5 \mathrm{mg} / \mathrm{ml})$, in comparison with other extracts. Recently, many reports demonstrated that the extracts of Tagetes erecta inhibited S. aureus, P. aeruginosa, $K$. pneumoniae, and $P$. mirabilis [37-39]. Padalia and Chanda (2015) reported MIC values on those bacteria in the range of $62-1250 \mu \mathrm{g} / \mathrm{ml}$ [37]. 
TABLE 6: MIC and MBC values $(\mathrm{mg} / \mathrm{ml})$ of crude extracts and fractions of four selected plant materials.

\begin{tabular}{|c|c|c|c|c|c|c|c|}
\hline \multirow{2}{*}{ Plant species } & \multirow{2}{*}{ Part tested } & \multirow{2}{*}{ Fractions } & \multicolumn{5}{|c|}{$\mathrm{MIC} / \mathrm{MBC}(\mathrm{mg} / \mathrm{ml})$} \\
\hline & & & SA & SR & $\mathrm{KP}$ & EC & $\mathrm{PA}$ \\
\hline \multirow{4}{*}{ A. conyzoides } & \multirow{4}{*}{ Aerial parts } & Cru.Ext & $2.5 / 2.5$ & $10 / 20$ & $5 / 5$ & $25 / 25$ & - \\
\hline & & $\mathrm{CHCl}_{3}$ & $20 / 40$ & $20 / 40$ & - & - & - \\
\hline & & EtOAc & $2.5 / 5$ & $5 / 10$ & $2.5 / 2.5$ & $10 / 10$ & - \\
\hline & & EtOH & $20 / 20$ & - & $10 / 20$ & - & - \\
\hline \multirow{4}{*}{ T. erecta } & \multirow{4}{*}{ Flower } & Cru.Ext & $0.78 / 1.56$ & $3.13 / 6.25$ & $1.25 / 1.25$ & - & $2.5 / 2.5$ \\
\hline & & $n-$ hexan & $1.56 / 3.12$ & - & $5 / 5$ & - & - \\
\hline & & $\mathrm{CHCl}_{3}$ & $1.56 / 3.12$ & - & $5 / 5$ & - & - \\
\hline & & EtOAc & $3.13 / 3.13$ & $6.25 / 12.5$ & $2.5 / 2.5$ & - & $5 / 5$ \\
\hline \multirow{3}{*}{ C. morifolium } & \multirow{3}{*}{ Flower } & Cru.Ext & $30 / 30$ & - & - & - & - \\
\hline & & $\mathrm{CHCl}_{3}$ & $15 / 30$ & - & - & - & - \\
\hline & & EtOAc & $15 / 15$ & - & - & - & - \\
\hline \multirow{2}{*}{ T. officinale } & \multirow{2}{*}{ Aerial parts } & Cru.Ext & $20 / 20$ & - & - & - & - \\
\hline & & EtOAc & $10 / 10$ & - & - & - & - \\
\hline
\end{tabular}

Cru.Ext: ethanol crude extract; —: no inhibitory zone.

TABLE 7: Determination of minimum inhibitory concentration (MIC) of essential oils.

\begin{tabular}{lccccc}
\hline \multirow{2}{*}{ Essential oils } & \multicolumn{5}{c}{$\mathrm{MIC} / \mathrm{MBC}(\mu \mathrm{l} / \mathrm{ml})$} \\
& SA & SR & CA & CG & CT \\
\hline A. conyzoides & $3.75 / 7.50$ & - & - & $7.5 / 15$ & $10 / 20$ \\
A. vulgaris & $2.50 / 2.50$ & $6.25 / 6.25$ & $6.25 / 12.5$ & $5 / 10$ & $5 / 10$ \\
H. annuus & $3.75 / 7.50$ & - & - & - & $10 / 20$ \\
\hline
\end{tabular}

Antimicrobial activity on uropathogenic strains of $E$. coli and $K$. pneumoniae.

Ageratum conyzoides aerial part extracts had an effect on MSSA, MRSA, K. pneumoniae, and E. coli, but the MIC values were higher than $T$. erecta extracts. Amadi et al. demonstrated that ethanol extract of $A$. conyzoides displayed the significant inhibitory zone on Streptococcus mutans [40]. Following the report of Akinyemi et al. (2005), ethanol extract from $A$. conyzoides indicated MIC and MBC on MRSA of $43 \mu \mathrm{g} / \mathrm{ml}$ and $63.2 \mu \mathrm{g} / \mathrm{ml}$, respectively [41]. Kouame et al. studied essential oils extracted from flower and stem of $A$. conyzoides [42]; the results displayed antibacterial activities with MIC in the range of 64 to $256 \mu \mathrm{g} / \mathrm{ml}$ on both Gram-positive and Gram-negative bacteria [42]. In this study, the MIC values were higher than the previous reports [41, 42]; these differences can relate to the dissimilarity of the time of sampling and extraction condition.

Ethyl acetate fractions (EA) from A. conyzoides, T. erecta, C. morifolium, and T. officinale showed activities against $S$. aureus. It is worth noting that EA from $A$. conyzoides and $T$. erecta displayed considerable impacts on Gram-negative bacteria including E. coli, K. pneumoniae (for A. conyzoides), and $P$. aeruginosa (for T. erecta). However, evaluating these EA on uropathogenic isolates revealed that merely the EA of Ageratum conyzoides expressed the capacity against uropathogenic isolates. Particularly, it was active against E. coli and $K$. pneumoniae producing ESBL, the strains that were highly resistant in clinical infection. Hence, Ageratum conyzoides is a good candidate for antiuropathogenic bacteria.
TABle 8: Antimicrobial activity of the ethyl acetate fraction of $A$. conyzoides determined by agar well diffusion assay.

\begin{tabular}{|c|c|}
\hline Strains & $\mathrm{IZD}(\mathrm{mm})$ \\
\hline E3 & 10.83 \\
\hline E7 & 11.43 \\
\hline E25 & 12.17 \\
\hline E36 & 13.33 \\
\hline E77 & 13.43 \\
\hline E38 & 13.67 \\
\hline E27 & 14.47 \\
\hline E39 & 14.47 \\
\hline E84 & 14.97 \\
\hline E68* & 15.43 \\
\hline E63 & 20.37 \\
\hline E51 & 21.40 \\
\hline E42 & 22.37 \\
\hline E94 & 22.37 \\
\hline E72 & 23.27 \\
\hline K18 & 9.33 \\
\hline $\mathrm{K} 27$ & 10.03 \\
\hline K19 & 11.23 \\
\hline K20 & 11.37 \\
\hline K15 & 11.67 \\
\hline $\mathrm{K} 23$ & 11.83 \\
\hline K14 & 11.93 \\
\hline $\mathrm{K} 21$ & 12.10 \\
\hline K28 & 12.37 \\
\hline K25 & 13.23 \\
\hline K22 & 13.27 \\
\hline K16 & 14.20 \\
\hline K29 & 17.67 \\
\hline $\mathrm{K} 26^{*}$ & 19.27 \\
\hline K17 & 19.73 \\
\hline
\end{tabular}

${ }^{*}$ ESBL-producing strain.

A. conyzoides, A. vulgaris, and $H$. annuus essential oils expressed antimicrobial activities against both bacteria (MSSA and MRSA) and yeasts (C. albicans, C. glabrata, and C. tropicalis). Our investigations witnessed anti-MRSA and anti-Candida effects of $A$. vulgaris essential oil. Those 


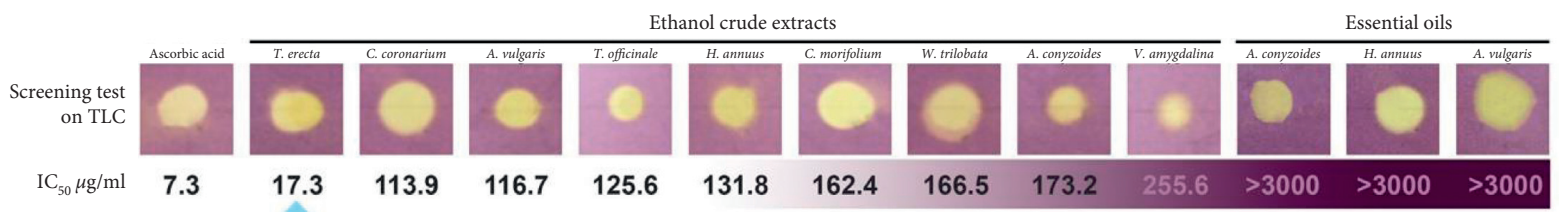

(a)

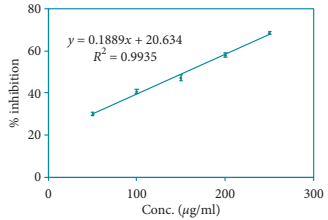

(A)

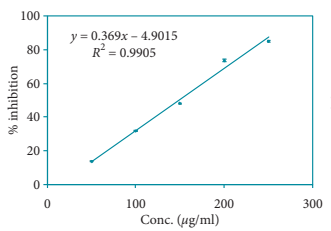

(F)

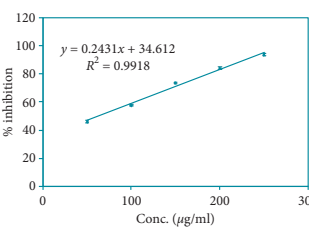

(B)

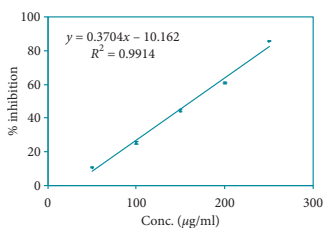

(G)

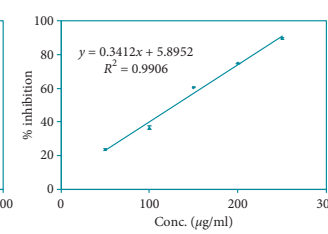

(C)

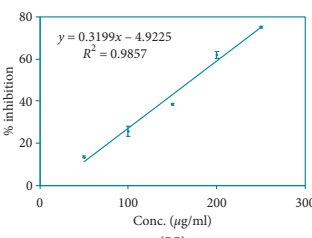

(H)

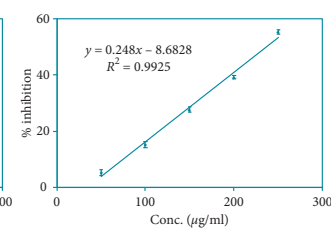

(D)

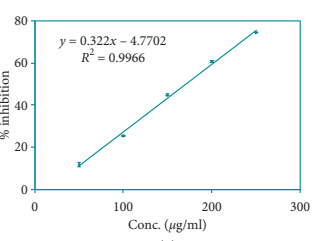

(I)

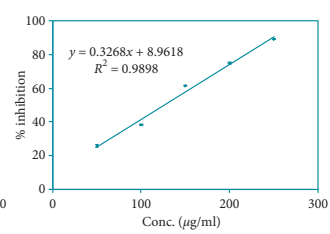

(E)

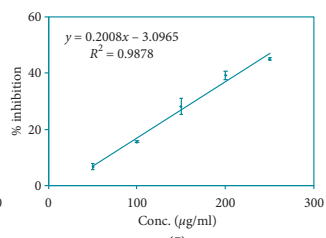

(J)

(b)

Figure 2: (a) DPPH screening test on TLC and $\mathrm{IC}_{50}$ values. (b) The plotted graphs of scavenging activity against the concentration of the ethanol crude extracts and ascorbic acid. A. Ascorbic acid. B. T. erecta. C. C. coronarium. D. A. vulgaris. E. T. officinale. F. H. annuus. G. C. morifolium. H. W. trilobata. I. A. conyzoides. J. V. amygdalina.

capacities could be attributed to a large amount of monoand sesquiterpenes compounds such as sabinene, $\beta$-thujone, chrysanthenone, camphor, and borneol in A. vulgaris oil [43].

$\mathrm{DPPH}$ is a free radical, stable at room temperature, which produces a violet solution in methanol. It is reduced in the presence of antioxidant molecules, making the color of the solution turned yellow. The use of DPPH provides an easy and rapid way to evaluate antioxidants.

All nine ethanol extracts were capable of capturing $\mathrm{DPPH}$ free radicals. T. erecta extracts had the lowest $\mathrm{IC}_{50}$ value, $17.3 \mu \mathrm{g} / \mathrm{ml}$, which is only 2.4 times higher than the $\mathrm{IC}_{50}$ value of ascorbic acid. This result could be due to the presence of a large amount of flavonoid and phenolic compounds in $T$. erecta as mentioned in preliminary phytochemicals. In the previous studies, marigolds displayed to contain quercetagetin, glucoside of quercetagetin, phenolics, syringic acid, methyl 3,5-dihydroxy-4-methoxy benzoate, quercetin, thienyl, and ethyl gallate [44]. Quercetin and ethyl gallate are potent antioxidant compounds in both in vitro and in vivo [45-47]. Containing many compounds with strong free-radical scavenging effects of $T$. erecta showed the ability for treatment of diseases caused by free radicals such as cancer, diabetes, and cardiovascular. However, this capacity needs to be evaluated more accurately by in vivo tests.

\section{Conclusions}

The fraction of ethyl acetate extracted from A. conyzoides possesses antimicrobial activities on uropathogenic E. coli and $K$. pneumoniae collected from District 2 Hospital, Ho Chi Minh City, Vietnam. This fraction is the potential to apply for healthcare serum in prophylactic recurrence UTIs. $T$. erecta showed the highest potent in $\mathrm{DPPH}$ radical scavenging assay, which could become a good candidate for the antioxidative agent in food and cosmetic products.

\section{Data Availability}

The data that support the findings of this study are available from the corresponding author upon reasonable request.

\section{Conflicts of Interest}

The authors declare that there are no conflicts of interest regarding the publication of this paper.

\section{Acknowledgments}

The authors would like to express their gratitude to Associate Professor Nguyen Dinh Nga for providing the clinical microorganisms. This study was financially supported by University of Medicine and Pharmacy at Ho Chi Minh City, through Grant no. 240-17.

\section{References}

[1] R. F. Potter, A. W. D'Souza, and G. Dantas, “The rapid spread of carbapenem-resistant Enterobacteriaceae," Drug Resistance Updates, vol. 29, pp. 30-46, 2016.

[2] L. K. Logan and R. A. Weinstein, "The epidemiology of carbapenem-resistant Enterobacteriaceae: the impact and evolution of a global menace," The Journal of Infectious Diseases, vol. 215, no. 1, pp. S28-S36, 2017. 
[3] M. H. Legese, G. M. Weldearegay, and D. Asrat, "Extendedspectrum beta-lactamase-and carbapenemase-producing Enterobacteriaceae among Ethiopian children," Infection and Drug Resistance, vol. 10, pp. 27-34, 2017.

[4] Y.-Y. Liu, Y. Wang, T. R. Walsh et al., "Emergence of plasmidmediated colistin resistance mechanism mcr-1 in animals and human beings in China: a microbiological and molecular biological study," The Lancet Infectious Diseases, vol. 16, no. 2, pp. 161-168, 2016.

[5] J. Abbasi, "Infectious disease expert sees threat from colistinresistant superbug," JAMA, vol. 316, no. 8, pp. 806-807, 2016.

[6] A. L. Flores-Mireles, J. N. Walker, M. Caparon, and S. J. Hultgren, "Urinary tract infections: epidemiology, mechanisms of infection and treatment options," Nature Reviews Microbiology, vol. 13, no. 5, pp. 269-284, 2015.

[7] B. Foxman, "Urinary tract infection syndromes: occurrence, recurrence, bacteriology, risk factors, and disease burden," Infectious Disease Clinics of North America, vol. 28, no. 1, pp. 1-13, 2014.

[8] K. A. Kline, D. J. Schwartz, W. G. Lewis, S. J. Hultgren, and A. L. Lewis, "Immune activation and suppression by group B streptococcus in a murine model of urinary tract infection," Infection and Immunity, vol. 79, no. 9, pp. 3588-3595, 2011.

[9] G. R. Nielubowicz and H. L. Mobley, "Host-pathogen interactions in urinary tract infection," Nature Reviews Urology, vol. 7, no. 8, p. 430, 2019.

[10] A. Ronald, "The etiology of urinary tract infection: traditional and emerging pathogens," The American Journal of Medicine, vol. 113, no. 1, pp. 14-19, 2003.

[11] H. C. Voon, R. Bhat, and G. Rusul, "Flower extracts and their essential oils as potential antimicrobial agents for food uses and pharmaceutical applications," Comprehensive Reviews in Food Science and Food Safety, vol. 11, no. 1, pp. 34-55, 2012.

[12] J. M. Kalwij, "Review of the Plant List, a working list of all plant species," Journal of Vegetation Science, vol. 23, no. 5, pp. 998-1002, 2012.

[13] M. B. Theodore, B. Luc, and L. S. John, "Asteraceae in flora of North America," 2006, http://www.efloras.org/florataxon. aspx?flora_id=1\&taxon_id=10074.

[14] M. J. Abad, L. M. Bedoya, and P. Bermejo, "Essential oils from the Asteraceae family active against multidrug-resistant bacteria," in Fighting Multidrug Resistance with Herbal Extracts, Essential Oils and Their Components, pp. 205-221, Elsevier, Amsterdam, Netherlands, 2013.

[15] I. Jallali, Y. Zaouali, I. Missaoui, A. Smeoui, C. Abdelly, and R. Ksouri, "Variability of antioxidant and antibacterial effects of essential oils and acetonic extracts of two edible halophytes: Crithmum maritimum L. and Inula crithmoïdes L," Food Chemistry, vol. 145, pp. 1031-1038, 2014.

[16] A. Jamalian, M. Shams-Ghahfarokhi, K. Jaimand, N. Pashootan, A. Amani, and M. Razzaghi-Abyaneh, "Chemical composition and antifungal activity of Matricaria recutita flower essential oil against medically important dermatophytes and soil-borne pathogens," Journal de mycologie medicale, vol. 22, no. 4, pp. 308-315, 2012.

[17] H. Sebai, M.-A. Jabri, A. Souli et al., "Antidiarrheal and antioxidant activities of chamomile (Matricaria recutita L.) decoction extract in rats," Journal of Ethnopharmacology, vol. 152, no. 2, pp. 327-332, 2014.

[18] A. A. Shahat, A. Y. Ibrahim, and M. S. Elsaid, "Polyphenolic content and antioxidant activity of some wild Saudi Arabian Asteraceae plants," Asian Pacific Journal of Tropical Medicine, vol. 7, no. 7, pp. 545-551, 2014.
[19] N. Stanković, T. Mihajilov-Krstev, B. Zlatković et al., “Antibacterial and antioxidant activity of traditional medicinal plants from the Balkan Peninsula," NJAS - Wageningen Journal of Life Sciences, vol. 78, pp. 21-28, 2016.

[20] M. A. Rashid, M. N. Akhtar, A. Ashraf et al., "Chemical composition and antioxidant, antimicrobial and haemolytic activities of Crambe cordifolia roots," Farmacia, vol. 66, no. 1, pp. 165-171, 2017.

[21] A. Ashraf, R. A. Sarfraz, M. A. Rashid, and M. Shahid, "Antioxidant, antimicrobial, antitumor, and cytotoxic activities of an important medicinal plant (Euphorbia royleana) from Pakistan," Journal of Food and Drug Analysis, vol. 23, no. 1, pp. 109-115, 2015.

[22] A. L. Okunade, “Ageratum conyzoides L.(Asteraceae)," Fitoterapia, vol. 73, no. 1, pp. 1-16, 2002.

[23] J. D. Adams, C. Garcia, and G. Garg, "Mugwort (Artemisia vulgaris, Artemisia douglasiana, Artemisia argyi) in the treatment of menopause, premenstrual syndrome, dysmenorrhea and attention deficit hyperactivity disorder," vol. 3, pp. 117123, 2012.

[24] J. A. T. da Silva, L. Yonekura, J. Kaganda, J. Mookdasanit, D. T. Nhut, and G. Afach, "Important secondary metabolites and essential oils of species within the Anthemideae (Asteraceae)," Journal of Herbs, Spices \& Medicinal Plants, vol. 11, no. 1-2, pp. 1-46, 2005.

[25] S. K. Bardaweel, M. M. Hudaib, K. A. Tawaha, and R. M. Bashatwah, "Studies on the in vitro antiproliferative, antimicrobial, antioxidant, and acetylcholinesterase inhibition activities associated with Chrysanthemum coronarium essential oil," Evidence-Based Complementary and Alternative Medicine, vol. 2015, Article ID 790838, 6 pages, 2015.

[26] M. Lal, S. K. Chandraker, and R. Shukla, "Antimicrobial properties of selected plants used in traditional Chinese medicine," in Functional and Preservative Properties of Phytochemicals, pp. 119-143, Elsevier, Amsterdam, Netherlands, 2020.

[27] T. Lim, "Helianthus annuus" in Edible Medicinal and Nonmedicinal Plants, Springer, 2014.

[28] C. Khare, "Tagetes erecta Linn" in Indian Herbal Remedies: Rational Western Therapy, Ayurvedic, and Other Traditional Usage, Springer, Berlin, Germany, 2004.

[29] T. Lim, "Taraxacum officinale" in Edible Medicinal and Nonmedicinal Plants, Springer, Berlin, Germany, 2014.

[30] O. Alara, N. Abdurahman, S. Abdul Mudalip, and O. Olalere, "Phytochemical and pharmacological properties of Vernonia amygdalina: a review," Journal of Chemical Engineering and Industrial Biotechnology V2, vol. 80, p. 96, 2017.

[31] N. Balekar, T. Nakpheng, and T. Srichana, "Wedelia trilobata L.: a phytochemical and pharmacological review," Chiang Mai Journal of Science, vol. 41, no. 3, pp. 590-605, 2019.

[32] R. Maria, M. Shirley, C. Xavier et al., "Preliminary phytochemical screening, total phenolic content and antibacterial activity of thirteen native species from Guayas province Ecuador," Journal of King Saud University-Science, vol. 30, no. 4, pp. 500-505, 2018.

[33] N. T. T. Anh, T. C. Đông, and N. Đ. Nga, "Khảo sát mức độ nhạy cảm của Candida spp. với fluconazole (Study on susceptibility of Candida spp. to fluconazole)," Y Học TP Hồ Chí Minh, vol. 16, no. 1, pp. 83-85, 2012.

[34] N. K. Sethiya, M. M. M. Raja, and S. H. Mishra, "Antioxidant markers based TLC-DPPH differentiation on four commercialized botanical sources of Shankhpushpi (A Medhya Rasayana): a preliminary assessment," Journal of Advanced Pharmaceutical Technology \& Research, vol. 4, no. 1, p. 25, 2013. 
[35] S. Burt, "Essential oils: their antibacterial properties and potential applications in foods - a review," International Journal of Food Microbiology, vol. 94, no. 3, pp. 223-253, 2004.

[36] S. Chouhan, K. Sharma, and S. Guleria, "Antimicrobial activity of some essential oils - present status and future perspectives," Medicines, vol. 4, no. 3, p. 58, 2017.

[37] H. Padalia and S. Chanda, "Antimicrobial efficacy of different solvent extracts of Tagetes erecta L. flower, alone and in combination with antibiotics," Applied Microbiology: Open Access, vol. 1, p. 106, 2015.

[38] N. Dasgupta, S. Ranjan, P. Saha, R. Jain, S. Malhotra, and M. Saleh, "Antibacterial activity of leaf extract of Mexican marigold (Tagetes erecta) against different gram positive and gram negative bacterial strains," Journal of Pharmacy Research, vol. 5, no. 8, pp. 4201-4203, 2012.

[39] P. Verma and A. Verma, "Evaluation of antibacterial activity of different parts of Tagetes erecta," International Journal of Pharmacy and Life Sciences, vol. 3, no. 6, pp. 1766-1768, 2012.

[40] E. Amadi, C. Oyeka, R. Onyeagba, O. Ugbogu, and I. Okoli, "Antimicrobial screening of Breynia nivosus and Ageratum conyzoides against dental caries organisms," Journal of Biological Sciences, vol. 7, no. 2, pp. 354-358, 2007.

[41] K. O. Akinyemi, O. Oladapo, C. E. Okwara, C. C. Ibe, and K. A. Fasure, "Screening of crude extracts of six medicinal plants used in South-West Nigerian unorthodox medicine for anti-methicillin resistant Staphylococcus aureus activity," BMC Complementary and Alternative Medicine, vol. 5, no. 1, p. 6, 2005.

[42] B. K. F. P. Kouame, D. Toure, L. Kablan et al., "Chemical constituents and antibacterial activity of essential oils from flowers and stems of Ageratum conyzoides from Ivory coast," Records of Natural Products, vol. 12, no. 2, p. 160, 2018.

[43] B. P. Pandey, R. Thapa, and A. Upreti, "Chemical composition, antioxidant and antibacterial activities of essential oil and methanol extract of Artemisia vulgaris and Gaultheria fragrantissima collected from Nepal," Asian Pacific Journal of Tropical Medicine, vol. 10, no. 10, pp. 952-959, 2017.

[44] F. Nikkon, M. R. Habib, Z. A. Saud, M. R. Karim, A. K. Roy, and S. Zaman, "Toxicological evaluation of chloroform fraction of flower of Tagetes erecta L. on rats," International Journal of Drug Development and Research, vol. 1, no. 1, pp. 161-165, 2009.

[45] A. B. Bentz, "A review of quercetin: chemistry, antioxidant properties, and bioavailability," Journal of Young Investigators, vol. 19, no. 10, 2009.

[46] T. Kalaivani, C. Rajasekaran, and L. Mathew, "Free radical scavenging, cytotoxic, and hemolytic activities of an active antioxidant compound ethyl gallate from leaves of Acacia nilotica (L.) wild. Ex. Delile sub sp. Indica (Benth.) Brenan," Journal of Food Science, vol. 76, no. 6, pp. T144-T149, 2011.

[47] H. Le Son and N. P. Anh, "Phytochemical composition, in vitro antioxidant and anticancer activities of quercetin from methanol extract of Asparagus cochinchinensis (Lour.) Merr. tuber," Journal of Medicinal Plants Research, vol. 7, no. 46, pp. 3360-3366, 1999. 